\title{
STUDENT OLYMPIAD MOVEMENT AS A SEARCH TOOL AND PEDAGOGICAL WORK WITH GIFTED YOUTH: PRINCIPLES, CHARACTERISTICS, EXPERIENCE
}

(C) 2017

\author{
Repina Evgenia Gennadievna, candidate of economical sciences, \\ associate professor of the Chair of mathematical statistics and econometrics \\ Samara State University of Economics (Samara, Russian Federation)
}

\begin{abstract}
The paper deals with the principles of organization of the Olympiad student movement in the Russian Federation, the author describes the purpose of the student contests in higher educational institutions of the country. The considered problem is solved in the process of identifying gifted students and pedagogical work with talented youth. The author describes benefits of student participation in the Olympiad movement, both for students and for institutions of higher education. The paper contains advantages and disadvantages of conducting these activities. The emphasis is on the features of Russian student Olympiads in mathematics, namely in such a subject area as probability theory and mathematical statistics. The paper also contains experience accumulated by the Department of Mathematical Statistics and Econometrics for conducting the Russian student Olympiad on the basis of Samara State University of Economics. To train the Olympic team of the University a computer simulator developed by the teachers of the Department is used. This software which is a graphical multi-window interface allows teachers to interact with students. The computer program contains tasks of previous Russian student Olympiads of various levels.

Keywords: student Olympiad movement; gifted students; national student competition; features of probability theory and mathematical statistics; methods of students training; computer simulator; difficulty levels of Olympiad problems.
\end{abstract}

УДК $37.011 .31+140.8$

Статья поступила в редакцию 29.05.2017

\section{О КОНЦЕПЦИИ ФОРМИРОВАНИЯ ЭТИЧЕСКОГО МИРОВОЗЗРЕНИЯ УЧИТЕЛЯ}

(C) 2017

Салов Александр Игоревич, кандидат педагогических наук, доцент, ректор

Академия сочиального управления (2. Москва, Российская Федераџия)

Аннотащия. В статье показывается значение этического мировоззрения, являющегося своего рода «технологией» устранения злейших врагов человечества (терроризм, сепаратизм и т.д.), «технологией» выживания в ситуациях, выходящих за пределы повседневности, в приведении к общему нравственно-этическому знаменателю усилий людей по пресечению зла; указывается, что этическое мировоззрение учителя есть система «ценностей ценностей» как предельных смыслов жизни и деятельности, находящихся на устремленной в нравственно-ценностную действительность вертикали этического сознания, выступающих в форме ориентиров на пути движения к нравственным идеалам, на вершине которых находится идеал «человека Человечества»; осмысливаются различные точки зрения ученых относительно понимания ими понятия «концепция»; представляется концепция формирования этического мировоззрения учителя в процессе повышения педагогической квалификации, разработанная в следующей логике: 1. Обоснование идеи а) являющейся системообразующим звеном перехода от образующих ядро этического мировоззрения учителя базовых ценностей к цели; б) развертывающейся в идеал как образ желаемого, должного. 2. Определение цели в рамках перехода от базовых ценностей к идее. 3. Обоснование идеала, приближение к которому учителя, учащегося осуществляется через добро, синтезирующее базовые ценности. 4. Выявление морально-этических принципов формирования этического мировоззрения учителя. 5. Определение подхода к формированию этического мировоззрения учителя.

Ключевые слова: учитель; этическое мировоззрение; формирование; концепция; «ценности ценностей»; смысл жизни; добро; добродетель; идея; цель; идеал; «человек Человечества»; морально-этический принцип; этико-педагогический подход; содержание; назначение; сущность.

В современной социально-нравственной ситуации в мире значение приобретает этическое мировоззрением, которое приводит к общему нравственно-этическому знаменателю усилия людей по предотвращению терроризма, террористических актов, насилия, по пресечению зла, обеспечивает выживание людей в различных ситуациях, являющимся, по мнению С.К. Бондыревой и Д.В. Колесова, механизмом «продолжения жизни в самых различных условиях окружающего мира» [1, с. 3].

Этическое мировоззрение является своего рода «технологией» устранения злейших врагов человечества (терроризм, сепаратизм и т.д.), «технологией» выживания в ситуациях, выходящих за пределы повседневности.

Этическое мировоззрение учителя, как это было обосновано нами ранее, «проявляемое в категориальной форме, есть система «ценностей ценностей» как предельных смыслов жизни и деятельности, находящихся на устремленной в нравственно-ценностную действительность вертикали этического сознания; определяющих понимание мира как его образа в культуре; передающих по цепи своих смыслов морально-этические принципы, ориентирующие педагога на создание нравственно-ценностного пространства; выступающих в форме ориентиров на пу- 
ти движения к нравственным идеалам, на вершине которых находится идеал «человека Человечества», выражающий отношение к миру и к подлинной нравственно-ценностной действительности, к самому себе» [2, с. 267].

Для решения задачи формирования такого мировоззрения учителя требуется разработка концепции, которая придаст направленность конструированию модели развития этического мировоззрения педагога. Для этого необходимо определиться с понятием «концепция».

Анализ тематически связанных с нашей работой исследований показывает, что ученые при разработке различных концепций опираются на предложенное В.И. Загвязинским и А.Ф. Закировой определение данного понятия: «Концепция есть система идей, взглядов и объяснений, которая, будучи упорядочена и доказана, может перерасти в теорию. Концепция выражает определенный способ видения, понимания каких-либо предметов, явлений, процессов. В отличие от теории, в концепции делается акцент не на когнитивном, логическом, а на ценностном начале, социокультурном значении вырабатываемого знания и области его применения» [3, с. 70].

На такое понимание В.И. Загвязинским и А.Ф. Закировой концепции опираются А.В. Бездухов, разрабатывающий концепцию формирования этического сознания будущего учителя [4, с. 138], И.М. Шадрина, разрабатывающая этико-педагогическую концепцию формирования нравственной культуры будущего учителя [5, с. 140-141].

Опираясь на предложенное В.И. Загвязинским и А.Ф. Закировой определение понятия «концепции» А.В. Бездухов и И.М. Шадрина определяют ведущую идею разработанных в контексте уровней методологии концепций формирования этического сознания будущего учителя и нравственной культуры будущего учителя соответственно. Это есть то общее, которое объединяет ученых при разработке концепций. Различное заключается в следующем. А.В. Бездухов исходит из того, что в основаниях концепции формирования этического сознания будущего учителя «находятся субъектно-ценностный, гуманистический и проблемно-методологический подходы, реализуемые с помощью соответствующих им принципов формирования этического сознания студентов. Принципом, обеспечивающим реализацию субъектно-ценностного подхода к формированию этического сознания будущего учителя, является принцип интеграции этического и педагогического знания. Принципами, обеспечивающими реализацию гуманистического подхода к формированию этического сознания будущего учителя, являются принцип перехода «добра в себе и для себя» учителя в «добро в себе и для себя» учащегося, принципы гуманизма, комплементарности нравственных отношений и ценностного синтеза нравственных миров. Принципами, обеспечивающими реализацию проблемно-методологического подхода к формированию этического сознания будущего учителя, являются принципы единства оценочного и ценностного, рефлексивной направленности процесса обучения, а также принципы морального выбора» [4, с. 159-160]. И.М. Шадрина в отличие от А.В. Бездухова исходит из положения В.Н. Сагатовского о том, что идея «конкретизируется в принцип - основное правило, предписывающее способ реализации идеи на пути движения к идеалу» [6, с. 19], и разрабатывает этико-педагогическую концепцию формирования нравственной культуры будущего учителя в следующей логике: «1. Выявление принципов, предписывающих способ реализации идеи «Быть достойным человеком - значит обладать добродетелями». 2. Определение похода к формированию нравственной культуры будущего учителя. 3. Определение деятельности, обеспечивающей реализацию подхода. 4. Раскрытие содержания философского, общенаучного и конкретно-научного уровней методологии» [5, с. 150].

Мы при разработке концепции формирования этического мировоззрения учителя исходим из того, что ядром этического мировоззрения учителя являются базовые ценности, которые как «ценности ценностей» [7, с. 256] выходят за грань конкретной деятельности педагога, обеспечивают нравственный порядок в отношениях между педагогом и учащимися, между людьми. Учет данного положения при разработке концепции является необходимым, но не достаточным. Важно учитывать, что «системообразующим звеном перехода от ценности, отвечающей на вопрос: «Во имя чего?», к норме-проекту (цели и задачи, отвечающим на вопросы: «Что и как делать?»), является идея, развертывающаяся в идеал» [8, c. 123]. Согласно В.Н. Сагатовскому, «идея, разворачивающаяся в стратегическую концепцию, образ желаемого и должного, фундированный целостной картиной мира, < ..> превращается в идеал» [8, с. 123].

Мы видим, что в понимании В.Н. Сагатовского концепция есть не просто совокупность идей, как у В.И. Загвязинского и А.Ф. Закировой. Напротив, идея разворачивается в концепцию как образ желаемого и должного. Опираясь на данное методологическое положение ученого, мы вначале выявляем являющуюся системообразующим звеном перехода от базовых ценностей к цели идею, которая превращается в идеал. Представим логику разработки концепции формирования этического мировоззрения учителя в процессе повышения педагогической квалификации: 1. Обоснование идеи а) являющейся системообразующим звеном перехода от образующих ядро этического мировоззрения учителя базовых ценностей к цели; б) развертывающейся в идеал как образ желаемого, должного. 2. Определение цели в рамках перехода от базовых ценностей к идее. 3. Обоснование идеала, приближение к которому учителя, учащегося осуществляется через добро, синтезирующее базовые ценности. 4. Выявление морально-этических принципов формирования этического мировоззрения учителя. 5. Определение подхода к формированию этического мировоззрения учителя.

Идеей, с обоснования которой мы начинаем разработку концепции, является одна из ведущих мировоззренческих идей - идея добра, созидание которого осуществляется на пути, движение по которому указывается целью - Мир на Земле. Простого указания на то, что добро является одной из ведущих мировоззренческих идей и идеей концепции, явно не достаточно. Требуется конкретизация идеи добра, разворачивающейся в концепцию формирования этического мировоззрения учителя. Конкретизированное понимание добра мы находим у Я.А. Миль- 
Салов А.И.

нер-Иринина, отмечающего, что «добро же всегда остается добром и никогда не вырождается во зло. Оно всегда и неизменно, при всем его непрерывном историческом обогащении, остается верховным идеалом, верховным принципом и верховной целью истинно человечного, нравственного существования. Добро есть истина в идеале, правде в идеале, красота в идеале, высший синтез этих высших идеальных ценностей, претворяемый реально творчески-созидательной деятельностью общественно-исторического человека во все возможные блага в новом, очеловеченном мире и новом же, очеловеченном человеке» [9, с. 91].

Такое понимание Я.А. Мильнер-Ирининым добра становится методологическим ориентиром для выявления идеи, разворачивающейся в концепцию формирования этического мировоззрения учителя, образ желаемого, должного и развертывающейся в идеал. Такой идеей является следующая идея: «Добро есть истина и правда в идеале - человек Человечества, есть синтез «ценностей ценностей»». Мы сознательно не включили в ведущую идею ценность «красота». Это объясняется тем, что методологической основой нашего исследования является этика, а не эстетика. В противном случае перед нами встала бы задача выявления «этажей» взаимодействия между этикой и эстетикой, педагогикой и эстетикой. Выявление таких «этажей» взаимодействия между данными науками - это задача отдельного междисциплинарного специально-научного исследования.

Мы в полной мере не осмысливаем категорию «идеал», не осуществляем ее науковедческий анализ, ибо это не входит в задачи нашего исследования. Однако заметим, что в исследованиях, тематически близких нашему, как было обозначено выше, представлен достаточно широкий спектр определений идеала.

Так, в исследовании Л.В. Вершининой, посвященном проблеме формирования ценностного сознания будущего учителя, представлены предлагаемые Е.Л. Дубко и В.А. Титовым, М.С. Каганом, Г.П. Выжлецовым, Р.Г. Апресяном определения категории «идеал» $[10$, с. 43-46]. Ученый осмысливает категорию «идеал» с целью выявления связи идеала с ценностью, с ценностным сознанием. Ю.В. Лопухова в исследовании, посвященном проблеме воспитания толерантности студентов вуза, дополняя представленный Л.В. Вершининой список определений данной категории, приводит предлагаемые Ю.В. Согомоновым и П.А. Ландесманом, И.И. Докучаевым определения категории «идеал» [11, с. 95-97]. Заметим, что ученый осмысливает категорию «идеал» с целью выявления признаков, которым отвечает толерантность как моральный идеал.

Мы в отличие от Л.В. Вершининой и Ю.В. Лопуховой в данной части нашей работы обращаемся к категории «идеал» с целью выявления того, что из себя представляет образ желаемого и должного, в который разворачивается идея «Добро есть истина и правда в идеале - человек Человечества, есть синтез "ценностей ценностей"». В этой связи для нашего исследования важной является, во-первых, мысль Г.П. Выжлецова о том, что идеал есть «единство желаемого и должного» [12, с. 58]; во-вторых, мысль Р.Г. Апресяна о том, что идеал - это «образ совер- шенства в отношениях между людьми» [13, с. 233]. Мы выбрали именно эти определения категории «идеал» потому, что идея, согласно В.Н. Сагатовскому разворачивается в стратегическую концепцию, образ желаемого и должного. Идеал, согласно Г.П. Выжлецову, есть «единство желаемого и должного», согласно Р.Г. Апресяну, идеал есть «образ совершенства в отношениях между людьми». Таким идеалом, в котором желаемое и должное находятся в единстве, и который есть «образ совершенства в отношениях между людьми» является идеал «человека Человечества» [14, с. 291]. «Человек Человечества», которого призван воспитывать учитель, есть человек Мира, который, противостоя злу, борясь с ним, способствует достижению Мира на Земле, благу других людей. Из этого следует, что идея «Добро есть истина и правда в идеале - человек Человечества, есть синтез "ценностей ценностей"» разворачивается в образ желаемого и должного, каким и является идеал человека Человечества.

Данная идея, разворачивающаяся в концепцию формирования этического мировоззрения учителя, в образ желаемого, должного, каким является идеал человек Человечества, синтезирует вокруг себя базовые ценности как «ценности ценностей». Суть синтеза базовых ценностей в идее, с нашей точки зрения, заключается в том, что добро, находящееся на вершине иерархии ценностного ряда базовых ценностей, проникая в их содержание, объединяет ценности таким образом, что каждая из них через свое содержание приближает учителя, учащегося к идеалу человека Человечества, доопределяет «действительный нравственный порядок, выражающий, безусловно, должное и, безусловно, желательное отношение каждого ко всему и всего к каждому» [15, с. 201]. Такое проникновение добра в содержание базовых ценностей, объединение приближающих учителя, учащегося к идеалу человека Человечества «ценностей ценностей» есть «нечто само в себе оправданное, как достойное, заслуживающее одобрения, долженствующее быть» [16, с. 61].

Стремление учителя, учащихся приблизиться к такому идеалу очеловечивает мир, очеловечивает человека. К идеалу можно приблизиться, но достичь его нельзя. Идея является системообразующим звеном перехода от базовых ценностей к цели - Мир на Земле, которую способен достигать человек Человечества. На основе выступающих в качестве предельных смыслов базовых ценностей учитель создает не просто образ мира, он формулирует перед собой и учащимися цель - Мир на Земле.

Следующим шагом на пути разработки концепции формирования этического мировоззрения учителя, согласно представленной выше логики, является выявление морально-этических принципов формирования этического мировоззрения учителя, ориентирующих осуществляющего повышение педагогической квалификации учителей преподавателя на реализацию идеи «Добро есть истина и правда в идеале - человек Человечества, есть синтез "ценностей ценностей"». В данном случае мы поступаем аналогичным образом, что и И.М. Шадрина, которая при разработке этико-педагогической концепции формирования нравственной культуры будущего учителя опирается на положение В.Н. Сагатовского, о том, 
Салов А.И.

что идея «конкретизируется в принцип - основное правило, предписывающее способ реализации идеи на пути движения к идеалу» [6, с. 19]. Мы не можем не повторить в данной части нашей работы эту мысль ученого, поскольку, в противном случае, будет не совсем понятно, почему следующим шагом разработки концепции является выявление морально-этических принципов. Главное же в том, что будет не понятно, что является методологической основой такого выявления. Такой основой и является указанное выше положение В.Н. Сагатовского об идее. Заметим, что мы ведем речь не просто о принципах, как И.М. Шадрина [5, с. 150], или Ю.В. Лопухова [11, с. 154], или А.В. Бездухов [17, с. 32], но о морально-этических принципах, формулируемых «в понятиях морального блага и моральной ценности» [18, с. 254]. Эти принципы, ориентируя преподавателя на формирование этического мировоззрения учителя, приближают и преподавателя, и учителя к идеалу.

Такими морально-этическими принципами являются принцип верности нравственно-ценностному педагогическому пространству; принцип диктата гуманистической совести; принцип реальности; принцип ценностного синтеза; принцип морального резонанса; принцип нередуцируемости морального блага; принцип правды; принцип ценностной ориентации.

Морально-этические принципы, как это было обосновано нами ранее, ориентируют учителя на совместный с учащимися поиск смысла жизни, который проясняет им отношения с миром, жизненный мир педагога и учащихся; существует в их сознании в виде образа мира, в форме смысловых структур; обеспечивает регуляцию их совместной деятельности в соответствии с логикой жизненной необходимости - Мир на Земле. Таким смыслом жизни и для учителя, и для учащихся, и для всех людей доброй воли в современной социально-нравственной ситуации являются добро и добродетель [19, с. 189].

Морально-этические принципы задают учителю исходную аксиому (во имя чего?) - во имя достижения цели - Мир на Земле, стратегию движения по избранному пути (каков путь?) - созидание добра для себя и для учащихся, которые, став взрослыми, консолидируются вокруг ценностей и идеалов в целях решения глобальных проблем современности, предотвращения угроз национальной безопасности государства, общества и личности в лице терроризма, влекущего за собой человеческие жертвы, разрушающего личность человека, культурное наследие, порождающего ненависть и недоверие к этносам, социальным группам.

Следуя представленной логике разработки концепции формирования этического мировоззрения учителя в процессе повышения педагогической квалификации, мы определяем подход к формированию этического мировоззрения учителя. В процессе наших исследовательских поисков мы пришли к убеждению, что таким подходом должен стать этикопедагогический подход. Прежде чем привести доказательства возможности использования этого подхода к формированию этического мировоззрения учителя, заметим, что этико-педагогический подход это не новый подход в педагогической науке. Анализ педагогических исследований, тематически близких с нашим, показывает, что этот подход был использован О.К. Поздняковой в исследовании проблемы формирования нравственного сознания будущего учителя [20, с. 72-74].

Сформулированные ученым положения об этикопедагогическом подходе были дополнены в совместной с В.П. Бездуховым статье, посвященной проблеме формирования ценностных ориентаций будущего учителя [21].

Суть такого дополнения заключается в том, что, если в своем исследовании О.К. Позднякова отмечает, что данный подход представлен на общенаучном и конкретно-научном уровнях методологии [20, c. 72], то в совместной с В.П. Бездуховым статье справедливо, с нашей точки зрения, подчеркивается, что этико-педагогический подход в первой его части относится к философскому уровню методологии, а во второй его части - к конкретно-научному уровню методологии [21, с. 19-20].

Мы дополняем ряд идей О.К. Поздняковой об этико-педагогическом подходе. Соглашаясь с ученым в том, что в содержании данного подхода в первой его части мы имеем дело с теорией морали в целом и с теорией педагогической морали в частности, что во второй его части представлены педагогические явления, заметим, что термин «этический» означает не только «относящийся к этике». Этот термин на языке морали означает, что проблеме морали уделяется особое значение. Подтверждение сказанному мы находим у А.А. Скворцова, который употребляет этот термин в словосочетании «этический поворот»: «Этический поворот - ситуация в современном гуманитарном знании, в которой проблемам этики уделяется повышенное, часто первостепенное значение» [22, с. 306].

Опираясь на данную мысль А.А. Скворцова, скажем, что речь в данном случае идет уже не столько о том, что этическое знание придает моральную направленность педагогическому знанию, наполняет его моральным содержанием, сколько о том, что педагогическое знание «поворачивается» к этическому знанию. Это означает, что в педагогике следует уделять особое внимание этическому, моральному знанию, что, однако, не ведет к утрате педагогикой статуса науки об образовании и воспитании.

Дальнейший анализ педагогических исследований показывает, что этико-педагогический подход используется И.М. Шадриной в исследовании, посвященном проблеме формирования нравственной культуры будущего учителя [5, с. 157-160]. Ученый дополняет ряд сформулированных О.К. Поздняковой и В.П. Бездуховым положений об этико-педагогическом подходе. В частности, И.М. Шадрина обращает внимание на то, что ученые, раскрывая суть этической составляющей этико-педагогического подхода, не акцентируют внимания собственно на этическом подходе. Опираясь на идеи В. Момова об этическом подходе, служащим этической науке в познании и овладении нравственной действительностью [23, c. 326], И.М. Шадрина, подчеркивает, что этический подход, обеспечивая познание такой действительности, «позволяет идентифицировать нравственные феномены и явления, среди которых находится нравственная культура учителя» [5, с. 159].

Важно отметить, что И.М. Шадрина, исходя из того, что этико-педагогический подход есть методо- 
логический подход, определяющий «принципиальную методологическую ориентацию» [24, с. 69], подчеркивает, что этот подход ориентирует преподавателя педагогического вуза на реализацию идеи концепции формирования нравственной культуры будущего учителя. Это, с нашей точки зрения, является весьма важным в деле реализации идеи «Добро есть истина и правда в идеале - человек Человечества, есть синтез "ценностей ценностей"» в процессе формирования этического мировоззрения учителя.

Для нашего исследования важной представляется мысль И.М. Шадриной о том, что «поскольку педагогика разрабатывает способы творения добра, постольку в педагогической составляющей данного подхода заключены способы творения добра. Такими способами являются нравственные правила вежливости, скромности и т.д., в которых будущий учитель, воспитывая себя, творит добро» [5, с. 159].

Следует также отметить, что И.М. Шадрина раскрывает сущность, назначение и содержание этикопедагогического подхода к формированию нравственной культуры будущего учителя. Мы также раскрываем сущность, назначение и содержание этико-педагогического подхода к формированию этического мировоззрения учителя, но в другой логике.

Методологической основой раскрытия содержания этико-педагогического подхода к формированию этического мировоззрения учителя является положение В.Н. Сагатовского об этическом отношении: «Этическое отношение: что есть добро и как его творить?» [6, с. 178].

Заметим, что на данное положение ученого опираются А.В. Бездухов, И.М. Шадрина и др. Так, А.В. Бездухов, выделяя в качестве структурных компонентов этического сознания учителя этическое знание и этическое отношение, подчеркивает, что добро является системообразующим для этического отношения: «Признание добра в качестве системообразующего для этического отношения по определению следует из понимания такого отношения В.Н. Сагатовским» [25, с. 260].

Соглашаясь с А.В. Бездуховым в том, что добро является системообразующим для этического отношения, мы полагаем, что речь должна идти не просто о добре, но о добре, которое «есть истина и правда в идеале - человек Человечества, есть синтез "ценностей ценностей"».

И.М. Шадрина, в качестве одного из компонентов содержания этико-педагогического подхода к формированию нравственной культуры будущего учителя наряду с педагогическим и нравственным отношением выделяет «этическое отношение в значении, что есть добро и добродетель как цель морали» [5, c. 177]. Видим, что ученый ведет речь не просто о добре, но о добре как цели морали.

Содержание этико-педагогического подхода к формированию этического мировоззрения учителя образуют этическое отношение в значении «Добро есть истина и правда в идеале - человек Человечества, есть синтез "ценностей ценностей"», находящихся на устремленной в нравственно-ценностную педагогическую действительность вертикали этического сознания (ранее было: «этическое отношение в значении, что есть добро и добродетель как цель морали». - И.М. Шадрина), и педагогическое отношение, в котором учитель воспроизводит а) стоящие за деятельностью по формированию морального миро- воззрения учащихся «ценности ценностей», которые определяют понимание мира как его образа в культуре; передают по цепи своих смыслов моральноэтические принципы, ориентирующие педагога на создание нравственно-ценностного педагогического пространства; б) синтезируемые этическим мышлением учителя категории этики, значением которых обладают «ценности ценностей», выступающие в форме ориентиров на пути движения к идеалу «человек Человечества».

Назначением этико-педагогического подхода к формированию этического мировоззрения учителя является создание преподавателем нравственно-ценностного педагогического пространства, содержание которого образуют выходящие за грань педагогической деятельности, обеспечивающие нравственный порядок в отношениях между педагогом и учащимися, между людьми предельные смыслы жизни или «ценности ценностей» как отношения.

Сущность этико-педагогического подхода к формированию этического мировоззрения учителя заключается в том, что он направлен на развитие способности педагога: 1) к пониманию того, что освоенные им ценности задают направленность выявлению таких находящихся на горизонтальной плоскости значений (ось культуры), которые познаются педагогом в познавательной деятельности, наделяются смыслом в ценностно-ориентационной деятельности и, воплощаясь в деятельности по формированию морального мировоззрения учащихся, способствуют гуманизации картины мира, становлению гармонии мира; 2) к пониманию того, что находящиеся на вертикали этического сознания «ценности ценностей» освящают поиск таких новых значений на оси культуры, которые, будучи освоенными и осмысленными, придают ценность всему тому, что входит в нравственно-ценностное педагогическое пространство, на вершине которого находится стремящийся к добру и к благу «человек Человечества» (ось бытия).

\section{СПИСОК ЛИТЕРАТУРЫ:}

1. Бондырева С.К., Колесов Д.В. Выживание (факторы и механизмы). М.: МПСИ; Воронеж: НПО «МОДЭК», 2005. 368 с.

2. Салов А.И. Вертикаль этического сознания учителя как ядра его этического мировоззрения // Мир психологии. 2016. № 4 (88). С. 262-268.

3. Загвязинский В.И., Закирова А.Ф. Сборник заданий по практической методологии педагогического исследования. Тюмень: ТГУ, 2009. 90 с.

4. Бездухов А.В. Теоретические основы формирования этического сознания студента - будущего учителя. М.: МПСУ; Самара: ПГСГА, 2014. 208 с.

5. Шадрина И.М. Теоретические основы формирования нравственной культуры будущего учителя. Мурманск: МГГУ, 2015. 196 с.

6. Сагатовский В.Н. Философия развивающейся гармонии (философские основы мировоззрения). В 3 ч. Ч. 1. Введение: философия и жизнь. СПб.: СПбГУ, 1997. 224 с.

7. Согомонов Ю.В., Ландесман П.А. Этапы становления мировоззренческих представлений в нравственном сознании // Моральный выбор / под общ. ред. А.И. Титаренко. М.: МГУ, 1980. С. 251-280.

8. Сагатовский В.Н. Философия развивающейся гармонии (философские основы мировоззрения). В 3 ч. Ч. 3. Антропология. СПб.: Петрополис, 1999. $288 \mathrm{c}$. 
9. Мильнер-Иринин Я.А. Этика, или Принципы истинной человечности. М.: Наука, 1999. 520 с.

10. Вершинина Л.В. Теоретические основы формирования ценностного сознания будущего учителя. М.: МПСИ, 2009. 258 с.

11. Лопухова Ю.В. Теоретические основы воспитания толерантности студентов вуза. М.: Московский психолого-социальный университет, 2012. 197 с.

12. Выжлецов Г.П. Аксиология культуры. СПб.: СПбГУ, 1996. 152 с.

13. Гусейнов А.А., Апресян Р.Г. Этика. М.: Гардарики, 2007. 472 с.

14. Братусь Б.С. Личностные смыслы по А.Н. Леонтьеву и проблема вертикали сознания // Традиции и перспективы деятельностного подхода в психологии: школа А.Н. Леонтьева. М.: Смысл, 1999. С. 284 298.

15. Соловьев В.С. Оправдание добра: нравственная философия. М.: Республика, 1996. 479 с.

16. Лосский Н.О. Условия абсолютного добра. М.: Политиздат, 1991. 368 с.

17. Бездухов А.В. О концепции формирования этического сознания будущего учителя // Известия
Самарского научного центра Российской академии наук. 2014. Т. 16, № 2. С. 29-33.

18. Шрейдер Ю.А. Этика. М.: Текст, 1998. 271 с.

19. Салов А.И. Морально-этические принципы как предмет педагогической рефлексии // Самарский научный вестник. 2016. № 3 (16). С. 189-194.

20. Позднякова О.К. Теоретические основы формирования нравственного сознания будущего учителя. М.: МПСИ, 2006. 168 с.

21. Бездухов В.П., Позднякова О.К. Этико-педагогический подход к формированию ценностных ориентаций будущего учителя и принципы его реализации // Педагогика. 2010. № 6. С. 15-26.

22. Скворцов А.А. Этика. М.: Юрай, 2012. 306 с.

23. Момов В. Теоретические проблемы нравственного воспитания // Предмет и система этики. М.: Институт философии АН СССР; София: Институт философии БАН, 1973. С. 323-345.

24. Юдин Э.Г. Методология науки. Системность. Деятельность. М.: Эдиториал УРСС, 1997. 444 с.

25. Бездухов А.В. Структура этического сознание учителя // Вестник Тверского государственного университета. 2013. № 26. Серия «Педагогика и психология». Вып. 4. С. 254-263.

\section{THE CONCEPT OF THE TEACHER'S ETHICAL WORLDVIEW FORMATION}

(C) 2017

Salov Alexander Igorevich, candidate of pedagogical sciences, associate professor, rector Academy of Public Administration (Moscow, Russian Federation)

\footnotetext{
Abstract. The paper shows the importance of an ethical world view, which is a kind of «technology» for eliminating the worst enemies of mankind (terrorism, separatism, etc.), the «technology» of survival in situations that go beyond everyday life, leading to a common moral and ethical denominator of people's efforts to suppress evil; it is pointed out that the ethical worldview of the teacher is a system of «values of values» as the ultimate meanings of life and activity that are directed towards the moral and value reality of the vertical of ethical consciousness, acting in the form of guidelines on the path of movement toward moral ideals, on top of which there is the ideal of «the man of Mankind»; different points of view of scientists as to their understanding of the concept «concept» are being comprehended; the concept of the formation of the ethical worldview of the teacher in the process of improving the pedagogical qualification is developed in the following logic: 1 . The rationale for the idea a) being the backbone of the transition from the core of the ethical worldview of the teacher of basic values to the goal; b) unfolding into the ideal as an image of the desired. 2. Defining the goal within the transition from basic values to the idea. 3. Justification of the ideal, the approach to which the teacher, the student is carried out through the good, synthesizing the basic values. 4. Identification of moral and ethical principles for the formation of the ethical worldview of the teacher. 5. Defining the approach to the formation of an ethical worldview teacher.

Keywords: teacher; ethical world view; formation; concept; «values of values»; meaning of life; goodness; virtue; idea; purpose; ideal; «man of Mankind»; moral and ethical principle; ethic-pedagogical approach; content; purpose; essence.
}

\section{ПОЛИФУНКЦИОНАЛЬНАЯ ПОДГОТОВКА БУДУЩИХ УЧИТЕЛЕЙ В КОНТЕКСТЕ ФЕДЕРАЛЬНЫХ ГОСУДАРСТВЕННЫХ ОБРАЗОВАТЕЛЬНЫХ СТАНДАРТОВ И ПРОФЕССИОНАЛЬНОГО СТАНДАРТА ПЕДАГОГА}

\footnotetext{
Семенов Александр Алексеевич, кандидат биологических наук, доцент, заведующий кафедрой биологии, экологии и методики обучения Соловьева Вера Валентиновна, доктор биологических наук, профессор кафедры биологии, экологии и методики обучения
}

Яицкий Андрей Степанович, старший преподаватель кафедры биологии, экологии и методики обучения Самарский государственный соџиально-педагогический университет (2. Самара, Российская Федераџия)

Аннотащия. Педагогическая деятельность носит полифункциональный характер. Полифункциональность деятельности педагога продиктована требованиями федеральных государственных образовательных стан- 